\title{
Demographic Transition, Human Capital And Growth
}

\author{
Luis Currais (E-mail: currais@udc.es), Economic Analysis, La Coruña University, Spain
}

\begin{abstract}
This paper firstly deals with the evolution of the literature on fertility and mortality growth rates and secondly discusses the extent to which both fertility and mortality affect the population growth rate as an endogenous variable. We develop an economic growth model using an infinite horizon setup in which economic development and health status influence the population growth rate. Mortality depends on health expenditure and fertility is endogenously determined. Each generation of family is linked altruistically and adults within each household take into account the welfare and resources of their actual and future descendants. The current generation maximizes utility and incorporates a budget constraint over an infinite horizon. Their decisions determine not also the evolution of the population growth rate but even the evolution of the per capita income.
\end{abstract}

\subsection{Introduction}

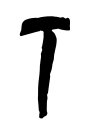

he effects of economic factors on fertility and mortality were a central element in development for Malthus (1798). Other economists such as Adam Smith (1776), Schumpeter (1954) and David Hume (Rostow, 1990) also discussed the link between population and subsistence resources. According to their predictions, rising prosperity would yield a greater increase in population growth until a food supply limit was reached. Although the findings of empirical studies do not support the "Malthusian paradigm" (Kremer, 1993, page 158) its impact meant that population began to be treated as an endogenous element derived from economic and social conditions.

This work is restricted to studies which are related to the problem of population and growth. We analyze the evolution of fertility and mortality rates and other important facets of population growth literature. It can be observed that the changes in reproductive behavior, which occur during the economic development process are strongly linked to the transformation of traditional agricultural economies with rudimentary technology, into modern societies. Before this transition takes place fertility rates are high and the use of contraception is virtually absent. Conversely, the vast majority of couples in developed societies limit their family size, which evolves according to the altruism of parents.

There are several factors that have crucial effects on fertility levels and their trends. Several authors have studied the relationship between fertility, population and economic growth and its consequences for development and well-being. Recent literature considers the mortality rate as an endogenous variable that depends fundamentally on health care. A genuine understanding of the economic growth process should contemplate the extent to which fertility and mortality affect the population growth rate, when considered as endogenous variables related to the socio-economic process.

This paper is organized into five sections. In the following section we briefly discuss previous results on fertility models. Section three discusses the results obtained by different authors taking into account mortality rates, health status and economic growth. In section four we present the an infinite horizon model in which economic

$\overline{\text { Readers with comments }}$ or questions are encouraged to contact the author via email. 
development and health status influence the population growth rate through heir impact on fertility and mortality rates. Our concluding remarks are given in the last section.

\subsection{The Role Of Fertility Models And Child Rearing Costs}

Prior to the 50s, apart from the Malthusian theory of population change, economists paid scarce attention to questions related to family and its consequences for fertility and the economic development process. Firstly Long (1958) and later Mincer (1962), argued that the participation of married women in the labor force is determined not only by their potential earnings, but also by their husbands' earnings, the number of children they have and other family characteristics.

A modern economic analysis of fertility began to replace the Malthusian analysis, and the parental demand for children has been shown to depend on family income, how parents value their time and the "quality" of children (Becker, 1960; Easterlin, 1968). Alternatively, several researchers looked at human capital investment, taking into account the relationship between parental investment in their children's education and the children's productivity (Schultz, 1963; Becker, 1994).

Following the work of Becker (1960) in which he analyses the behavior of demographic and economic changes in developed countries and the role of fertility, several authors have studied the feedback between population growth and development. Economists generally assume that there are two basic reasons to have children: the provision of material benefits to the family unit, and the consideration of children as pure "consumption goods" which implies the pleasure parents derive from their children's existence. In both cases the specifications which are used can be viewed as an expression of parents' altruism. The material benefits of having children might include the contribution of labor services to a family business or even in looking after parents in their old age. We therefore review the studies that have attempted to determine the extent to which these affect fertility rates and what this implies for population levels and growth.

The hypothesis which puts forward exogenous population growth as inherent in the neoclassical models, which neglect interactions between the economic growth process and demographic trends is clearly unsatisfactory. These models are unable to capture the observable diversity of population growth through the variance in the behavior of fertility and mortality rates among different countries. The neoclassical model offers a comprehensive, rigorous treatment of population and income variables, although per capita income growth is exogenously determined. Endogenous population growth literature has progressed along two basic theoretical lines of research. On the one hand, we find those studies that follow the neoclassical growth model where the economic growth rate is exogenously determined and, on the other those models based on endogenous economic growth.

The neoclassical model offers a comprehensive, rigorous treatment of population and income variables, although per capita income growth is exogenously determined. The analysis of endogenous population growth along with the analysis of several economic factors in different static and dynamic environments yields distinct results. In the literature of population and growth we can highlight the importance of certain factors like the quantity and quality of children and the effects of the social security system, and the role of intergenerational transfers. These factors are considered in either endogenous or exogenous economic growth research.

The first systematic analysis of the interaction between quantity and quality of children is offered in Becker and Lewis (1973). This is a static model, which stresses the role played by the desired human capital of children. The model therefore, does not allow us to analyze the dynamic aspects of the interaction between quantity and quality of children. Parents maximize a utility function where both quantity and quality enter as distinct elements, which are subject to a specific budget constraint. The model offers s simple explanation for the observation that when income increases the fertility rate decreases. The income elasticity of demand for quality is higher than that for quantity. Thus, when income increases the shadow price of quantity increases more than the shadow price of quality.

The work of Eckstein and Wolpin (1985) focuses on the role of the stock of human capital of working 
adults instead of stressing the role of desired human capital of children. The cost of children is a function of parents' income, which affects the cost of child rearing. They assume that per capita income is a function of human capital accumulation, and that they are positively correlated. In their model the fertility rate first rises and then falls, thus explaining a basic feature of the demographic transition. We may consider the models of Becker and Barro (1988) and Barro and Sala (1995) as extensions of the previous two models. Although Barro and Sala (1995) use a continuous time approach and Becker and Barro (1988) use an overlapping generations framework in two time periods, the general results are quite similar. Parental decisions about numbers of children are made jointly along with choices about consumption and intergenerational transfers. The choice of the number of children interacts with the determination of their quality, which depends on consumption and the quantity of capital stock allocated to each person. The fertility rate depends on the marginal utility attached to children, which diminishes with their number.

Intergenerational transfers and more specifically the social security system have potentially important implications for fertility behavior. Leibenstein (1963) was one of the firsts to argue that social security policies may reduce fertility. Weight was given to this assumption by various studies, some of which we highlight here. Nugent and Gillapsy (1983) and later Entwisle and Winegarden (1984) carry out similar empirical studies based on a crosssection analysis of groups of less developed countries. They also obtained similar results. Changes in the fertility rates are negatively related to the social security proxy variable, after controlling for other explanatory variables.

For Cadwell $(1976 ; 1982)$ in any society and at any stage of economic development the fertility rate is fundamentally determined by the direction of the intergenerational flow of wealth. In the less developed societies children contribute to their parents' wealth, while in developed societies it is the parents who leave bequests or invest in children's human capital. This process increases the cost of having children and consequently decreases the fertility rate.

A different approach is considered by Willis (1989). In order to analyze the role of old-age security on fertility he considers the existence of uncertainty with respect to one's longevity and imperfect annuity markets. He concludes that within this context fertility increases in comparison to a perfect market situation. Cigno and Rosati (1992) develop a three-stage finite horizon model in order to analyze the effect of social security on fertility. They compare the strength of parents' self interest and the intergenerational altruism through the impact of the social security system. The model considers that young working parents support their parents and "lend" resources to their children at a given interest rate, and then collect on these loans for old-age support, so children's utility is specified as a part of the parents' utility. Using Italian time series data they present three sets of results that depend on the relative strength of the selfish old-age security motive and the intergenerational altruism motive. Ehrlich and Lui (1991) realize a cross-section analysis for 65 countries, which includes both poor and rich countries. They find that, after controlling for GDP and measurements of both young-age and old-age longevity, social security benefits as a percentage of GDP in 1960 had a significant negative impact on the birth rate in 1965 and on the total fertility rate in 1975 in poor countries. For relatively rich countries however, they do not obtain the significant effects observed for poor countries.

An important conclusion can be derived from these studies. The quantity of children is not the only important variable within parental control. When we consider the quality of children and the availability of savings opportunities as complementary choice variables, the effect of the reduction on fertility due to the provision of old-age social security is not clear (see Wildasin, 1990, page 420; Ehrlich and Lui, 1998, page 401).

In the last few years research has contributed important new results to the literature on population and growth as endogenous variables. We take a look at some of the studies which are based on models where economic growth and population growth rates are endogenous and simultaneously determined as a result of distinct initial conditions or changes in the parameters of the model that yield economic growth.

The work of Becker, Murphy and Tamura (1990) represents an important reference point, since they have been the first to offer an endogenous population and growth model based on explicit micro-foundations that provide an explanation for some of the features of the demographic transition. In their model, the time parents spent on investing in the human capital of their children, and the number of children, are choice variables. The rates of return 
on investment, in both the quantity of children and their human capital, depend on both the level of human capital of the dynasty head and the chosen number of children. The per capita income growth and consumption are endogenous variables that depend on human capital, which is considered to be the engine of economic growth. The optimal solution of the model presents three steady-state equilibria: a stable state, which is a low-level state, with a low level of human capital and zero growth, an intermediate but unstable state of development, and a stable state of perpetual growth with higher human capital. If the initial level of human capital is higher than a threshold level, which is linked to the unstable development equilibrium, then human capital investment becomes more worthwhile, the fertility rate is lower than other equilibria, and growth is persistent. If the initial level of human capital is lower than this threshold level, the economy moves towards a Malthusian regime characterized by high fertility, no investment in children's human capital and no economic growth. Ehrlich and Lui $(1991 ; 1998)$ develop a three period overlapping generations model where young parents decide on the number of children, the amount of human capital investment per child and the expected material compensation from their children in old-age. Although their maximizing problem is subject to the same law of motion of human capital presented in the work of Becker, Murphy and Tamura (1990), the existence of intergenerational trade allows for implicit contracts between parents and children. This consideration eliminates the multiple equilibria of outcome and the problem of potential intergenerational externalities of the Becker, Murphy and Tamura model. The optimal solution is unique at any particular point in time. The motive for having children depends on the rate of return to parents which is a function of the life expectancy of children and parents, their time preference, the human capital technology and the optimal rate at which children compensate their parent's investment in them.

The latter two models share some key features. In both models the engine for growth is human capital and fertility behavior is a consequence of the relationship between quantity and quality of children. In a dynamic context there is a feedback effect between population and growth, which also depends on other factors that jointly determine the process of economic development. Although these dynamic relationships give us some insights into the association between income, education and fertility across economies, there are some aspects of the demographic transition that are not considered. The role of mortality, which is an important part of the demographic transition is not explicitly modeled. This gap in research might be filled by more fully analyzing the implications of human capital and health investment on longevity and fertility pointed out by various authors and supported by various studies which have been carried out by the World Bank and the World Health Organization, and which we discuss in next section.

\subsection{The Mortality Rate, Health Spending And Economic Growth}

Human health and its relevance to population growth is one of the great themes of human history. Although demographic changes and trends with respect to health are closely linked, they are often considered separately. The relationship between health and population is a two-way process that yields feedback. Each can be a determinant as well as a consequence of the other. The way in which they influence each other may be a fundamental factor when deciding public policy and intervention.

The world-wide situation today with respect to health is characterized by the huge differences in the mortality profiles of those who live in developed, developing or underdeveloped countries. In the most developed countries, there is an enhanced expectation of life at birth, an important component of which is improved survival in early life, particularly from birth to the first birth year. According to the World Bank Health Report (1993) and WHO (1993) there are four groups of factors which contribute decisively to high levels of life expectancy: rising incomes, health expenditure, improvements in medical technology, and shifts in social behavior and cultural factors such as education and in particular female education.

Each of these groups of factors has influenced the decline in mortality rates and increased life expectancy in different countries to varying degrees. The role of preventive and curative policy depends on the level of development of medical technology and the level of per capita health expenditure within the society. The contribution of any one specific factor to contemporary declines in mortality would be difficult to quantify, but these declines are certainly influenced by recent advances in medical technology and increases in health expenditure, whereas historically, declines in mortality were more as a result of economic factors such as education, nutrition and behavioral changes.

According to the World Bank, differences in health spending are an important starting point in the search 
for an explanation of the differences in health and mortality rates among countries. In 1990, total annual health spending ranged from less than $\$ 10$ per person in several African and Asian countries to more than $\$ 2.700$ in the United States. There was also considerable variation within regions. In Africa, Tanzania spent only $\$ 4$ per capita on health in 1990, while Zimbabwe spent $\$ 42$ per person. In Asia, Bangladesh spent $\$ 7$ per person each year, as against $\$ 377$ in Korea. Since the share of GNP devoted to health tends to rise with income, the difference between what rich and poor countries spend on health is even greater than their difference in income. As a consequence of this, life expectancy ranges from forty years or less in some countries in Sub-Saharan Africa to seventy-five or more in developed economies. In Sub-Saharan Africa half of all deaths occur below the age of 5. In the developed economies half occur after the age of 74. Child mortality rates exceed 200 per 1.000 in several African countries but are below 20 in the richest countries. The level of disease, in per capita terms, is five times higher in developing regions than in the healthiest regions. Falls in mortality and morbidity rates, which are linked to per capita health expenditure and their consequences for a healthier population and work force, are important in promoting economic productivity and fomenting economic development. In the long run the benefits of improved health are also likely to influence the way work is organized and carried out.

Endogenous population growth literature also points out the important link between human capital and health economics theories and their consequences for fertility and longevity (Grossman, 1972; Ehrlich and Chuma, 1990). Different authors focus on the relationship between population, growth and human capital, stressing the role of health by using different theoretical and empirical approaches. In studying the implications of health economics on economic growth Barro and Sala (1995, page 432) find that life expectancy should be considered as an important growth factor. They calculate that a 13 year increase in life expectancy would yield an increase in the annual growth rate by 1.4 percentage points.

Jablonski, Rosemblum and Kunze (1988) obtain similar empirical conclusions for life expectancy. They study the relationship between life expectancy, productivity and health. Their results support the theoretical and empirical findings of Currais and Rivera (1999a; 1999b) where health expenditure, used as a proxy of health status, increases productivity through its effect on human capital accumulation. Estimates are made for the OCDE countries for the period 1960-90. They find that investment in health contributes in a significant way to explaining variations in output through human capital, even in those countries, which presumably have high levels of health. This result is justified fundamentally by the decrease in the depreciation rate of human capital and the reduction in morbidity which affects the mortality rate.

There are several empirical studies that study the positive correlation between higher per capita health expenditure and lower mortality rates (WHO, 1993; Kawachi et al., 1997). Beyond this relationship we find those works that analyze the positive impact of higher health spending on lower mortality rates and higher economic growth, which would be probably bounded in the most developed countries (World Bank, 1993; Fogel, 1997). Evidence obtained by these authors was very important in promoting new research based on dynamic models, which incorporate trends in mortality, fertility, intergenerational transfers and economic growth.

Recent works attempt to explain how developing economies have typically moved from a state of low per capita income, high mortality and high fertility to a regime of persistent growth in which first mortality, and then fertility are continuously declining while per capita income presents persistent growth. This phenomenon known as demographic transition is treated in the the following section.

\subsection{The Model}

This model is an extension to the fertility choice model of Becker and Barro (1988) and the continuous time approach proposed by Barro and Sala (1995). We consider an infinite horizon model were mortality depends on health expenditure and fertility is endogenously determined. Thus, each generation of family is linked altruistically and adults within each household take into account the welfare and resources of their actual and future descendants. The current generation maximizes utility and incorporates a budget constraint over an infinite horizon. We consider that altruistic parents provide transfers to their children, who also consider in turn their transfers to their children, and so on. 
Time is continuos and there are a large number of firms in the market that act competitively. Each firm hire labor $L$ and rent capital $K$ in competitive factor markets and sell their products in a competitive goods market. Firms take the technological progress $A$ as given and it grows at the rate $x$. They maximize their profits which are owned by households, thus households accrue profits.

At each point in time firms employ the stocks of labor $L$ and capital $K$ paying for their marginal products and selling the produced output. Each firm produces a flow of output $Y$ according to $Y=F(K, A L)$. The production function represents a labor-augmenting technological progress that occurs at the constant rate $x \geq 0$. In the Cobb-Douglas case we obtain that $\hat{y}=A \hat{k}^{\alpha}$, where $0<\alpha<1$, where $\hat{y}=y e^{-x t}$ and $\hat{k}=k e^{-x t}$ represent per capita income and per capita capital in terms of effective labor, respectively. Capital depreciates at the constant rate $\delta$ and firms pay the marginal product of factors $r=\alpha A \hat{k}^{\alpha-1}-\delta$ and $w=(1-\alpha) A \hat{k}^{\alpha} e^{x t}$.

The economy has a large number of identical households that seek to maximize utility. Their preferences are described by the intertemporal utility function

$U=\int_{0}^{\infty} e^{-\rho t}\{\psi \ln N+\ln c+\phi \ln (n-d(\hat{g}))\} d t$,

where $\rho$ is the rate of time preference and represents parental altruism, that corresponds to $\rho>0 . N$ is the size of a typical dynasty, $n$ and $d$ are the family's fertility and mortality rates respectively, and $c$ is the consumption of each member of the household. As exogenous growth rate of technological progress occurs at a constant rate $x$, so that $\hat{g}=g e^{-x t}$ is per capita health expenditure in terms of effective labor. Here, $d(\hat{g})$ is the family's mortality rate that depends on per capita health expenditure in terms of effective labor.

The use of the mortality rate as a function of health expenditure per efficiency unit of labor seeks to capture the effects highlighted by some empirical studies. Newhouse (1977) argue that the marginal unit of health care may contribute more to "caring" (or subjective components of health) than to "curing" (or physiological health). This result supports the conclusions of several studies using data on mortality and morbidity. According to Parkin et al (1987) it is equally plausible to assume that the marginal unit of medical care does produce an improvement in physiological health, but that the cost of this marginal unit is greater for higher income/higher expenditure countries. In this sense as cheaper diseases are eradicated by increased expenditure, more expensive diseases take their place.

By assumption, we take the function $d(\hat{g})$ as a $\mathrm{C}^{2}$ function verifying that $d(\hat{g}) \geq 0, d^{\prime}(\hat{g})<0$ and $d^{\prime \prime}(\hat{g})>0, \forall \hat{g} \geq 0$. In other words the mortality rate decreases as $\hat{g}$ increases, but the greater the expenditure the less its decrease. Some other desirable features might be that $\mathrm{d}(0)>0$. This means that with no health expenditure the mortality rate would be the "natural" mortality rate. Another desirable feature is that $\lim _{\hat{g} \rightarrow \infty} d(\hat{g})=\bar{d}$, with $0<\bar{d}<\mathrm{d}(0)$. This fact could be justified since health gains are effectively bounded. It signifies that under no circumstances the mortality rate falls below $\bar{d}$. The size of the family changes continuously according to

$\dot{N}=(n-d(\hat{g})) N$

The way that this model is developed means that one should interpret $d$ as representing infant mortality, thus $n-d$ is understood to be the number of surviving children. It is possible to interpret the analysis more generally by thinking in terms of a broad concept of death since mortality rates at all ages are likely to depend on some basic common factors. Households are competitive, thus each of them takes as given the interest rate $r$ and receives the same wage rate $w$ per unit of labor services. Each adult supplies inelastically one unit of labor per unit of time. The 
family`s assets $k$, considering the case of a close economy, earn the rate of return $r$.

We can also introduce the same relationship, proposed by different authors, between the individual per capita quantity of capital $k$ and the cost of child rearing $\Phi$. The cost of child rearing $\Phi$ would tend to increase with parents income or with other measures of the opportunity costs of parental time. We use instead a simplified linear function of child rearing costs, as follows:

$\Phi=b k$

where $b k$ represents the opportunity costs that increase with parental capital intensity.

The total per capita income received by each household is the sum of wages and interest income. Thus, the family`s budget constraint can be expressed as

$$
\dot{k}=w+[r-n+d(\hat{g})] k-b n k-c-g
$$

where $w$ is the wage rate and $r$ is the interest rate.

The household optimization problem lies in maximizing (1), subject to (2) and (3). Solving the model by using optimal control, we obtain the following expressions:

$$
\begin{aligned}
& \frac{\dot{\hat{c}}}{\hat{c}}=\alpha A \hat{k}^{\alpha-1}-\delta-\rho-b d(\hat{g})-\frac{\phi \rho(1+b) \hat{c}}{\rho(1+b) \hat{k}-\psi \hat{c}}-x, \\
& \frac{\dot{\hat{k}}}{\hat{k}}=A \hat{k}^{\alpha-1}-\delta-b d(\hat{g})-\frac{\phi \rho(1+b) \hat{c}}{\rho(1+b) \hat{k}-\psi \hat{c}}-\frac{\hat{c}}{\hat{k}}-\frac{\hat{g}}{\hat{k}}-x, \\
& \dot{\hat{g}}=-\frac{d^{\prime}(\hat{g})}{d^{\prime \prime}(\hat{g})} \frac{\dot{\hat{k}}}{\hat{k}} .
\end{aligned}
$$

The stability of the equilibrium can be studied making a linear approximation to (4) around the steady state. We can eliminate $\hat{k}$ and express (4) in terms of $\hat{c}$ and $\hat{g}$ as

$$
\begin{aligned}
& \frac{\dot{\hat{c}}}{\hat{c}}=\alpha A\left(-b d^{\prime}(\hat{g})\right)^{1-\alpha}-\delta-\rho-b d(\hat{g})+\frac{\phi b d^{\prime}(\hat{g}) \hat{c}}{1+\frac{\psi b d^{\prime}(\hat{g}) \hat{c}}{\rho(1+b)}-x,} \\
& \dot{\hat{g}}=-\frac{d^{\prime}(\hat{g})}{d^{\prime \prime}(\hat{g})}\left[A\left(-b d^{\prime}(\hat{g})\right)^{1-\alpha}-\delta-b d(\hat{g})+\frac{\phi b d^{\prime}(\hat{g}) \hat{c}}{1+\frac{\psi b d^{\prime}(\hat{g}) \hat{c}}{\rho(1+b)}}+b d^{\prime}(\hat{g})(\hat{c}+\hat{g})-x\right] .
\end{aligned}
$$

Working with $\hat{g}$ instead of $\hat{k}$ is not an inconvenient, since the relationship between $\hat{g}$ and $\hat{k}$ is one-to-one. Now let us make some assumptions about the function $d(\hat{g})$, and the parameters of the model. Firstly, we assume that the mortality rate is related to health expenditure through a negative exponential function:

$$
d(\hat{g})=L+M \exp \left\{T \hat{g}^{S}\right\}, \quad L, M, S>0 .
$$


In order for $d$ to be a decreasing function, then $T<0$. This function verifies all the desirable features for the mortality rate pointed out in the assumptions of the model. The natural mortality rate (in the absence of health expenditure) is $L+M$, and the threshold value of the mortality rate, which may not go below is $L$. The parameter $S$ is related to the rate of decreasing of the mortality rate. We consider the following benchmark taking into account the common parameters used in Barro and Sala (1995):

\begin{tabular}{|cccccccccccc|}
\hline$L$ & $M$ & $T$ & $S$ & $\alpha$ & $A$ & $b$ & $\rho$ & $\psi$ & $\phi$ & $\delta$ & $x$ \\
\hline 0.005 & 0.195 & -1 & 0.5 & 0.75 & 1 & 1 & 0.02 & 0.2 & 0.2 & 0.05 & 0.02 \\
\hline
\end{tabular}

The stability of equilibrium can be ascertained determining the Jacobian matrix of $\dot{\hat{c}}$ and $\dot{\hat{g}}$ in the steady state as

$$
J=\left(\begin{array}{cc}
-0.0176249 & -0.116627 \\
-0.00421637 & 0.0376249
\end{array}\right)
$$

whose eigenvalues are $\lambda_{1}=0.0454243$ and $\lambda_{2}=-0.0254243$, with associated eigenvectors respectively $(0.879683$,$0.47556)$ and $(-0.997771,-0.0667253)$. Hence, the model exhibits saddle-path stability.

Examining the Jacobian matrix we see that the $\dot{\hat{c}}=0$ locus is negatively sloped and stable, since $\dot{\hat{c}}$ declines for $\hat{c}$ for a given $\hat{g}$. The $\dot{\hat{g}}=0$ locus is positively sloped around the steady state, but is unstable since $\dot{\hat{g}}$ rises for $\hat{g}$ for a given $\hat{c}$. As the model exhibits saddle path stability, there is only one stable trajectory. We calculate the policy function $\hat{c}(\hat{g})$ for the stable arm by using the time elimination method of Mulligan and Sala (1993). The transitional path and the phase diagram are presented in figure I. The relationship between $\hat{c}$ and $\hat{g}$ along the locus $\dot{\hat{g}}=0$ is the solution to a quadratic equation which has two real positive roots for a range of reasonable parameters. The larger root always turns out to lie above the $\dot{\hat{c}}=0$. Thus, in figure I we only represent the smaller root of $\dot{\hat{g}}=0$. The figure shows that the transitional path is positively sloped. Hence, if the economy starts from a state of low initial per capita capital, one which is below its steady state value and where per capita health expenditure is low, capital and per capita health expenditure grow along the transition path towards the steady state.

Figure II shows that the fertility rate exhibits a monotonic behavior. It decreases towards its stationary value as the economy develops. The fertility and mortality rates are correlated in a significant and negative way with the per capita income. As the economy develops, the fertility and the mortality rates fall and are accompanied by an increase in per capita income. This behavior characterizes the so-called "modern growth regime" that the economy undergoes after the demographic transition [see Rostow (1990) and Maddison (1995)]. Reduced mortality levels and a healthier population are major contributors to a rise in living standards, which is often regarded as a major factor in fertility decline. Figure III shows the evolution of the mortality rate:

Figure I - Phase diagram in $(\hat{c}, \hat{g})$ space 


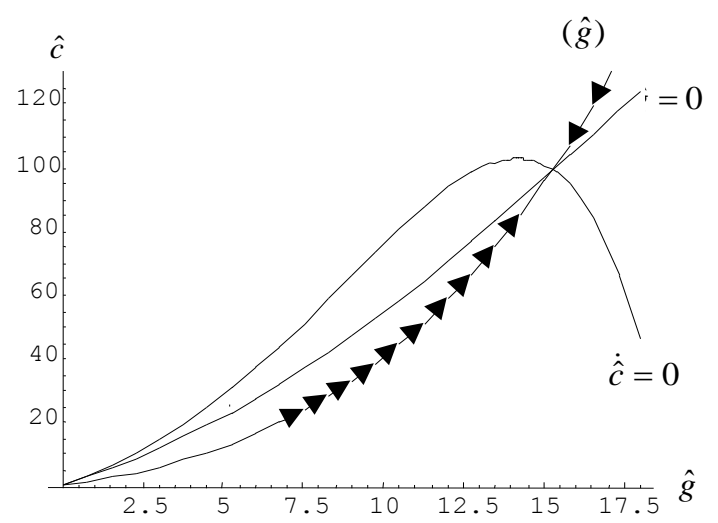

Figure II - Transitional behavior of the fertility rate

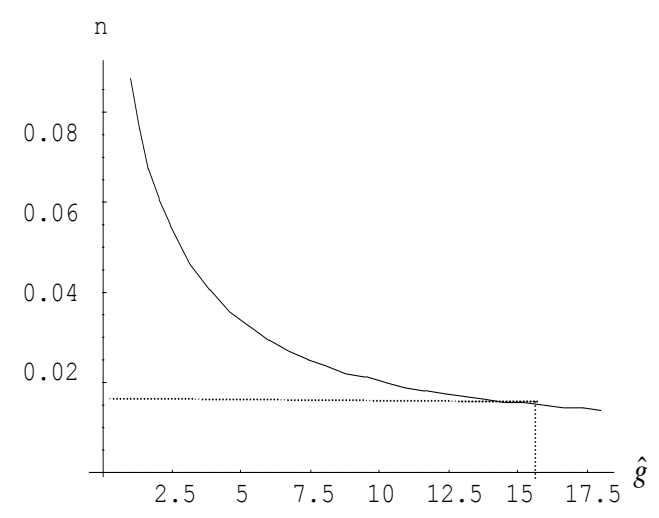

Figure III - The transitional behavior of the mortality rate

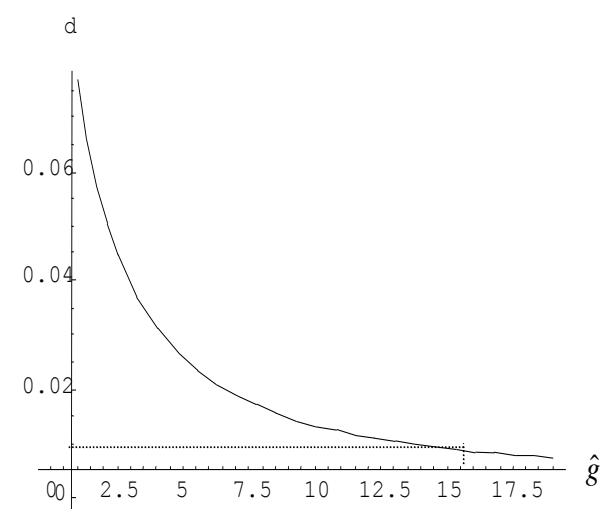

Table 1 presents the effect on the steady state values of the variables $\hat{c}, \hat{g}, \hat{k}, d, n$ and $r$ on changing in the designated parameter remaining all other in their baseline settings. 
Changes in $\psi$ and $\phi$ lead to changes of $n$ and $d$ in the same direction. That is a result which was expected, since the higher the value for $\psi$ or $\phi$, the greater the benefits in terms of utility with respect to the children. For instance when $\psi$ rises from its baseline value to 0.3 , the mortality rate increases from 0.0089 to 0.009285 and the fertility rate thus changes from 0.0155 to 0.0173 . The variation in the fertility rate is greater than the variation in the mortality rate reflecting the effect of the rising in $c / k$ from 0.0497 to 0.0502 . Hence, the net rate of population growth also rises from 0.00662 to 0.00807 .

Table 1: Effects of parameter variations

\begin{tabular}{|c|c|c|c|c|c|c|}
\hline Parameter & $\hat{c}^{*}$ & $\hat{g}^{*}$ & $\hat{k^{*}}$ & $d^{*}$ & $n^{*}$ & $R^{*}$ \\
\hline Baseli & 99.4829 & 15.2848 & 2000.01 & 0.0089095 & 0.0155303 & 0.0621511 \\
\hline$\psi=($ & 89.6172 & 14.5752 & 1781.68 & 0.0092855 & 0.0173624 & 0.0654393 \\
\hline$\psi=($ & 106.942 & 15.7882 & 2166.74 & 0.0086676 & 0.014298 & 0.0599284 \\
\hline$\phi=c$ & 76.6883 & 13.5553 & 1499.73 & 0.0099098 & 0.0202148 & 0.0705197 \\
\hline$\phi=\mathrm{C}$ & 128.379 & 17.1058 & 2653.21 & 0.0081176 & 0.0113091 & 0.0545005 \\
\hline$b=$ & 82.36 & 18.8953 & 1721.72 & 0.0075247 & 0.0113187 & 0.0664315 \\
\hline$b=c$ & 105.472 & 11.4461 & 2044.84 & 0.011618 & 0.0220995 & 0.0615312 \\
\hline$T=-($ & 65.5381 & 28.4455 & 1574.61 & 0.0185486 & 0.0238046 & 0.0690606 \\
\hline$T=-1$ & 108.618 & 9.37413 & 2067.29 & 0.0069747 & 0.0141009 & 0.0612271 \\
\hline$L=0.0$ & 88.647 & 14.5025 & 1760.36 & 0.0123266 & 0.019057 & 0.0657874 \\
\hline$L=0.0$ & 107.6 & 15.8314 & 2181.52 & 0.0066478 & 0.0131947 & 0.0597417 \\
\hline$M=0$. & 98.2051 & 16.9025 & 2007.08 & 0.0090967 & 0.0155744 & 0.0620521 \\
\hline$M=0$. & 100.777 & 13.6849 & 1993.64 & 0.0087111 & 0.0154758 & 0.0622404 \\
\hline
\end{tabular}

We note a similar pattern when $\phi$ increases to 0.3 , although this effect is stronger than that provoked by $\psi$ on $n$ and $d$. For example $n$ rises to 0.0202 and $d$ rises to 0.0099 which gives a net rate of population growth of 0.0103 . A variation in $b$ yields a change in the fertility rate in the opposite direction reflecting the importance of the child rearing cost. For example, as $b$ rises from 0.5 to 2 the fertility rate declines from 0.022 to 0.0113 . Furthermore, the mortality rate declines from 0.01161 to 0.00752 due to an increase in health expenditure. Since health expenditure is aimed at both children and adults, the higher the opportunity costs of child rearing are, the higher the value of their health. The rate for population growth decreases and changes from 0.0104 to 0.0037 as a result that $b$ has a stronger effect on the fertility rate than its effect on the mortality rate.

With respect to variations in the parameters that enter in the functional form of $d$ we can argue that changes in the natural mortality rate $(L+M)$, when the threshold value of $L$ is held constant, from its baseline value of 0.2 to 0.155 and 0.255 , yield slight variations in the mortality and the fertility rates, although it is almost unnoticeable. As we might expect changes in $L$ lead to similar changes in $d$ and $n$.

The steady state values of the mortality and fertility rates are quite sensitive to variations in the parameter $T$ which mainly affect the concavity of the mortality rate function. Changing the parameter $T$ from -0.5 to -1.5 yields a decrease in the mortality rate from 0.0185 to 0.0069 and a fall in the fertility rate from 0.0141 to 0.0238 . The greater the absolute value of $T$ the more effective is health expenditure on mortality rate. When $T$ is -1.5 health expenditure is 9.37 and the mortality rate is 0.0069 and when $T$ is -0.5 health expenditure is 28.44 and the mortality rate is 0.0185 . For variations in the parameter $T$, the value of per capita capital remains roughly in the same extent.

Variations in the parameters that affect the utility function, when holding the remainder parameters constant, which lead to greater per capita health expenditure also lead to greater per capita capital. From table 1, lesser mortality rate and greater per capita capital imply a lower fertility rate. These results support those obtained by Kirk (1996). Parents switch from quantity to quality of children in response to a rise in the rate of human return. Reduced mortality and a healthier population are major contributors to a rise in living standards, which is often regarded as a major factor in fertility decline. 
Increasing values of $\psi, \phi, b, L$ or $T$ yield increasing values for the steady state interest rate. In any case, the interest rate do not vary so much when parameters change and the fluctuation ranges from 0.054 to 0.070 .

\subsection{Conclusions}

In this paper we present a model in which the fertility rate and the mortality rate are endogenously determined and in which individual choice with respect to health expenditure is introduced. The result reveals a direct relationship between per capita health expenditure and per capita capital. During the transition path both variables evolve in the same direction. If the economy starts from a lower capital per capita point than its steady state value, per capita health expenditure and capital per capita rise jointly towards their steady state values, thus the mortality rate declines monotonically until it reaches its stationary value. This movement is consistent with observable evidence of increases in health expenditure and decreases in the mortality rate and in the fertility rate over time.

Per capita health expenditure and per capita income in the steady state are directly related: The greater the health expenditure the greater the income in the steady state. We also observe that a lower mortality rate and higher per capita capital implies a lower fertility rate. The fertility and mortality rates are correlated in a significant and negative way with the per capita income. As the economy develops, the fertility and the mortality rates fall and are accompanied by an increase in per capita income. These results are in accordance with the assertion that reduced mortality and healthier population are important contributors to higher living standards and increases on productivity, which are often regarded as a major factor in fertility decline.

\section{References}

1. Barro, R. J. and Sala, 1995, Economic growth, McGraw-Hill, New York.

2. Becker, G. S., 1960, An economic analysis of fertility in: Demographic and economic change in developed countries, a conference of universities-NBER Committee for Economic Research. Princeton University Press, Princeton, N. J.

3. Becker, G.S., 1994, A treatise on the family, Cambridge, Harvard University Press.

4. Becker, G. S. and R. Barro, 1988, A reformulation of the economic theory of fertility, Quarterly Journal of Economics, 103, 1-25

5. Becker, G. S. and H.G. Lewis, 1973, On the interaction between the quantity and quality of children, Journal of Political Economy, 81, S279-S288.

6. Becker, G. S., K. Murphy and R. Tamura, 1990, Human capital fertility and economic growth, Journal of Political Economy, 98, S12-S37.

7. Caldwell, J., 1976, Toward a restatement of demographic transition theory, Population and Development Review, 2, 321-366.

8. Caldwell, J., 1982, Theory of fertility decline, Academic Press, New York.

9. Cigno, A.y F. Rosati, 1992, The effects of financial markets and social security on saving and fertility behavior in Italy. Journal of Population Economics, n. 5, p. 319-341.

10. Currais, L. and B. Rivera, 1999a, Income variation and health expenditure: Evidence for OECD countries, Review of Development Economics, 3, 258-267.

11. Currais, L. and B. Rivera, 1999b, Economic growth and health: Direct impact or reverse causation, Applied Economic Letters, 6, 761-764.

12. Easterlin, R. A., 1968, Population, labor force and long swings in economic growth, Columbia University Press, New York.

13. Eckstein, Z. and K. Wolpin, 1985, Endogenous fertility and optimal population size, Journal of Public Economics, 27, 93-106.

14. Ehrlich, I. and H. Chuma, 1990, A model of the demand for longevity and the value of life extension, Journal of Political Economy, 98, 761-782.

15. Ehrlich, I. and F.T. Lui, 1991, Intergenerational trade, longevity and economic growth. Journal of Political Economy, n. 99, p. 1029-1059.

16. Ehrlich, I. and F.T. Lui, 1998, Social security, the family, and economic growth. Economic Inquiry, July, p. 390-409. 
17. Entwistle, B. and C.R. WinegardenINEGARDEN, 1984, Fertility and pension programs in LDCs: A model of mutual reinforcement. Economic Development and Cultural Change, n. 32, p. 331-354.

18. Fogel, R., 1997, New findings on secular trends in nutrition and mortality: Some implications for population theory. In: Mark Rosenzweig and Oded Stark (eds.), The handbook of population and family economics, v. 1A, North Holland, Amsterdam.

19. Grossman, M., 1972, The demand for health: A theoretical and empirical investigation, Columbia University Press, New York.

20. Jablonski, M., L. Rosemblum and K. Kunze, 1988, Productivity, age, and labor composition changes in the U.S., Monthly Labor Review, 111(9), 34-38.

21. Kawachi, I., Kennedy, P., Lochner, K. and D. Prothow-Smith, 1997, Social capital, Income Inequality and Mortality. American Journal of Public Health, v. 9, n. 87, p. 1491-1498.

22. Kremer, M., 1993, Population growth and technological change: One million B.C. to 1990.

23. Leibenstein, H., 1963, Economic backwardness and economic growth, Willey, New York.

24. Long, C. D., 1958, The labor force under changing income and employment, Princeton University Press, Princeton.

25. Maddison, A., 1995, Monitoring the world economy: 1820-1992, OCDE, Paris.

26. Malthus, T. R., 1798, An essay on the principle of population, W. Pickering, London.

27. Mincer, J., 1962, Labor force participation of married women. In: Aspects of Labor Economics, Princeton University Press, Princeton.

28. Mulligan, C. and X. Sala, 1993, Transitional Dynamics in two-sector models of endogenous growth, Quarterly Journal of Economics, 434, 739-773.

29. Newhouse, J. 1977, Medical care expenditure: A cross-national survey, Journal of Human Resources, 12, pp. 115-125.

30. Nugent, J.B. and R.T. Gillapsy, 1983, Old age pensions and fertility in rural areas of less developed countries: Some evidence from Mexico. Economic Development and Cultural Change, n. 31, p.809-830.

31. Parkin, D., A. McGuire and B. Yule, 1987, Aggregate health care expenditures and national income. Is health care a luxury good ?, Journal of Health Economics, 6, pp. 109-127.

32. Rostow, W., 1990, Theorists of economic growht from David Hume to the present, Oxford University Press, New York.

33. Schultz, T., 1963, The economic value of education, Columbia University Press, New York.

34. Schumpeter, J., 1954, History of economic analysis, Oxford University Press, New York.

35. Smith, A., 1776, An inquiry into the nature and causes of the wealth of nations, Random House, New York, 1937. English first edition.

36. Wildasin, D., 1990, Non-neutrality of debt with endogenous fertility. Oxford Economic Papers, n. 42, p. 414-428.

37. Willis, R. J., 1989, Public and private intergenerational transfers, economic growth and demographic transition, Academy Sinica, Taipei, Taiwan.

38. World Bank, 1993, World development report, Oxford University Press, New York.

39. World Health Organization, 1993, Health and mortality. WHO, Geneva. 